REFERENCE:

[1] Hamuryudan V, et al. Clin Exp Rheumatol 2016; 34: 1033

Acknowledgement Supported with an unrestricted grant from Pfizer Disclosure of Interests: Gizem Ayan: None declared, Sinem Nihal Esatoglu: None declared, Gulen Hatemi Consultant for: Abbvie, Amgen, BMS, Janssen, MSD, Pfizer, UCB, Speakers bureau: Abbvie, Amgen, BMS, Jansen, MSD, Pfizer, UCB, Vedat Hamuryudan Consultant for: Abbvie, Amgen, BMS, Jansen, MSD, Pfizer, UCB, Speakers bureau: Abbvie, Amgen, BMS, Jansen, MSD, Pfizer, UCB,

DOI: 10.1136/annrheumdis-2019-eular.984

\section{AB0242 RADIOLOGICAL EVALUATION OF FOREFOOT INVOLVEMENT IN RHEUMATOID ARTHRITIS}

Rym Fakhfakh, Saoussen Zrour, Abir Dghaies, Hibatallah Mosbeh, Olfa Jmaa, Grassa Rim, Jguirim Mahbouba, Ismail Bejia, Mongi Touzi, Naceur Bergaoui. $\mathrm{CHU}$ Fattouma Bourguiba, Rheumatology, monastir, Tunisia

Background: Severe and often debilitating involvement of the forefoot is seen frequently in patients with rheumatoid arthritis (RA)

Objectives: We aim to determine the prevalence and the characteristics of radiological forefoot involvement

Methods: Monocentric retrospective study of 52 consecutive patients with RA, hospitalized in the Rheumatology Department between 2012 and 2018. Radiological measurements included the modified Sharp/van der Heijde method (SHS) for the feet and forefoot angles: The angle between the longitudinal bisection of the first metatarsal and the first phalanx of the first finger (Hallux valgus: $\mathrm{H} 1 \mathrm{M} 1 \geq 20^{\circ}$ ), the intermetatarsal angle between the 1st and 2nd metatarsals (Metatarsus primus varus: $\mathrm{M} 1 \mathrm{M} 2 \geq 10^{\circ}$ ) and the intermetatarsal angle between the 1st and 5th metatarsals (splaying foot: $\mathrm{M} 1 \mathrm{M} 5 \geq 35^{\circ}$ ) measured on antéroposterior radiographs.

Results: The average age was $53 \pm 15$ years and the sex-ratio was 0.21 . The average disease duration was $8 \pm 10$ years and the average disease activity index DAS28 was $5.65 \pm 1.12$. The prevalence of forefoot erosion and joint space narrowing were $35 \%$ and $58 \%$, respectively. In $85 \%$ of patients, both $\geq 1$ forefoot erosion score and $\geq 1$ forefoot joint space narrowing score were present. Erosions were the most frequent in the $5^{\text {th }}$ metatarsophalangeal joints (MTP) and $1^{\text {st }}$ interphalangeal joint $(50 \%$ and $47 \%$ of eroded joints, respectively) and the least frequent in $4^{\text {th }}$ MTP $(27 \%)$. The forefoot erosion score was significantly correlated with age, disease duration and hand erosion score and weakly but statistically significantly with titer of ACPA $(p \leq 0.05)$. Obesity was an independent protective factor $(\mathrm{OR}=0.25 ; \mathrm{p}<0.05)$ of forefoot erosions. Foot deformities were observed in $71 \%$ of the patients; Metatarsus primus varus(MV) $(56 \%)$, hallux valgus(HV) (38.5\%) and splaying foot(SF) (13.5\%). The HV was significantly correlated with forefoot damage (erosion score $r=0.67$, joint space narrowing $r=0.7 ; p<0.01$ ), extra-articular manifestations of $R A$, disease duration and rheumatoid factor titer. Multivariate analysis showed that the extra-articular manifestations was an independent risk factor for HV $(\mathrm{OR}=9.39, \mathrm{p}<0.05)$. There was significant correlation between the $\mathrm{MV}$ and forefoot damage (erosion score: $r=0.4$, joint space narrowing: $r=0.5, p<0.05)$. There was no correlation between the splaying foot and the forefoot damage. The splaying foot was associated with the hallux valgus $(O R=5.7, p=0.05)$.

Conclusion: In our study, forefoot involvement is common in patients with RA and it isn't associated with disease severity. Deformities (HV, $\mathrm{MV}$ ) are associated with forefoot joint damage and splaying foot is associated with hallux valgus.

\section{REFERENCES:}

[1] Baan H, \& Drossaers-Bakker w, et al. We should not forget the foot: relations between signs and symptoms, damage, and function in rheumatoid arthritis. Clin Rheumatol (2011) 30:1475-1479

[2] Matsumoto, et al. Radiologic Patterning of Joint Damage to the Foot in Rheumatoid Arthritis. Arthritis Care \& Research.2014;66 (4):499-507.

Disclosure of Interests: None declared

DOI: 10.1136/annrheumdis-2019-eular.6967
AB0243

CYSTEINE RICH 61 (CYR61): A POTENTIAL BIOMARKER ASSOCIATED WITH DISEASE ACTIVITY IN RHEUMATOID ARTHRITIS

Yong Fan, Xinlei Yang, Juan Zhao, Xiaoying Sun, Wenhui Xie, Yanrong Huang, LI Guangtao, Yanjie Hao, Zhuoli Zhang. Peking University First Hospital, Department of Rheumatology and Clinical Immunology, Beijing, China

Background: Numerous preclinical studies have revealed a critical role of Cysteine rich 61 (Cyr61) in the pathogenesis of rheumatoid arthritis (RA). However, little is known about the potential value of circulation Cyr61 in clinical RA patients.

Objectives: To compare serum Cyr61 level in patients with RA and healthy controls, and to characterize the potential association between Cyr61 and RA disease activity.

Methods: In training cohort, serum samples were obtained from 177 patients with definite RA and 50 age- and gender- matched healthy controls. Medical records were collected and serum Cyr61 concentration was detected by enzyme-linked immunosorbent assay. Correlations between Cyr61 levels with clinical disease activity were analyzed. Furthermore, a validation cohort consisting of 77 active RA patients who received uniform biologic therapy for 12 weeks was set up (ClinicalTrials.gov identifier: NCT02320630). Paired serum samples were collected at baseline and after 12-week treatment for each individual and prepared for detection of Cyr61. Comparisons between groups were made using Mann-Whitney $U$ test or Wilcoxon matched-pairs signed rank test, as appropriate.

Results: Significant elevation of serum Cyr61 concentration was found in RA patients, demonstrating excellent diagnostic ability to discriminate RA with healthy controls (area under the curve $(A \cup C)=0.98, P<0.001$ ). In training cohort, Cyr61 level in active RA patients was significantly lower than that in inactive RA, and it was inversely with measures of clinical disease activity in statistic. Findings were further confirmed in our validation cohort. Active RA patients who had a reduction in disease activity showed a significantly increase of Cyr61 level after effective treatment (in terms of achieving ACR20/50/70 improvement criteria). RA patients who did not achieve ACR response showed no significant difference of Cyr61 level before and after treatment. Multivariate logistic regression analysis revealed that increase of Cyr61 level as well as younger age were independent indicators for achieving ACR20 response.

Conclusion: Serum Cyr61 levels were remarkably increased in RA patients compared with healthy control. More intriguingly, the level of Cyr61 was inversely associated with RA disease activity and increased after effective treatment.

\section{REFERENCES:}

[1] Zhang Q, Wu J, Cao Q, Xiao L, Wang L, He D, et al. A critical role of Cyr61 in interleukin-17-dependent proliferation of fibroblast-like synoviocytes in rheumatoid arthritis. Arthritis \& Rheumatism. 2009;60(12):3602-12.

[2] Chen CY, Su CM, Hsu CJ, Huang CC, Wang SW, Liu SC, et al. CCN1 Promotes VEGF Production in Osteoblasts and Induces Endothelial Progenitor Cell Angiogenesis by Inhibiting miR-126 Expression in Rheumatoid Arthritis. J BONE MINER RES. 2017 2017-01-01;32(1):34-45.

[3] Barranco C. CCN1, a novel RA target? NAT REV RHEUMATOL. 2016 2016-08-19;12(10):561.

Conflict of interest: The authors declare that they have no competing interests.

Disclosure of Interests: None declared

DOI: 10.1136/annrheumdis-2019-eular.5222

\section{AB0244 THE IMPORTANCE OF TREATMENT STRATEGY FOR THE OUTCOME OF EARLY RHEUMATOID ARTHRITIS PATIENTS NOT RESPONDERS TO THE FIRST LINE THERAPY WITH METHOTREXATE}

Anna Laura Fedele, Dario Bruno, Barbara Tolusso, Luca Petricca, Gianfranco Ferraccioli, Elisa Gremese. Fondazione Policlinico Universitario A. Gemelli IRCCS, Division of Rheumatology, Rome, Italy

Background: According to EULAR recommendations for the management of Rheumatoid Arthritis (RA), if the treatment target is not reached with the first conventional synthetic (cs)-disease modifying antirheumatic drugs (DMARDs), addition of another csDMARD or of a biological (b)-DMARD should be considered [1].

Objectives: To evaluate the clinical and radiological outcome under combination therapy of either cs-DMARDs or b-DMARDs in our cohort of early rheumatoid arthritis (ERA) patients treated according to the treat-totarget (T2T) strategy. 